\title{
King Abdulaziz University's Approach to International Collaboration
}

\author{
Abdulrahman Al-Youbi and Adnan H. M. Zahed
}

\section{Introduction}

This section first explains the differences between the terms "cooperation," "collaboration," and "partnership," which are used interchangeably in the literature. It then highlights the reasons King Abdulaziz University (KAU) that has chosen to collaborate with other academic and research institutes.

\subsection{Definition of Cooperation, Collaboration, and Partnership}

Cooperative work is accomplished by dividing a task among participants where each is responsible for a portion of it [1]. Cooperation is achieved if all participants do their assigned parts and send them back to the work coordinator. Cooperative bodies have specific and joint rights and responsibilities. Each cooperative body has an equal share of the risk as well as the reward. The concept of "international cooperation" describes cooperative activities between two or more countries. The policies of the participating partners are negotiated to bring agreements more in line with each side's preferences. Once policies become more compatible, the act of cooperation is completed [2, 3].

The term "collaboration" is the action of working together with others to produce or create something, and in the context of academic bodies, it is used mostly on the level of research. In other words, it is the mutual engagement of participants in a coordinated effort to solve a problem together [4]. However, the collaboration also involves cooperation, in which the responsibilities of each partner may not be shared equally.

Partnership is a co-term used in cooperation as well as collaboration to indicate that two or more partners are cooperating to conduct the task. Partnerships may be

A. Al-Youbi · A. H. M. Zahed ( $\square)$

King Abdulaziz University, Jeddah, Saudi Arabia

e-mail: azahed@kau.edu.sa between researchers in the same laboratory or academic department, between researchers from different departments in the same institution, or even between researchers in different institutions or different countries. The latter case may be sometimes complicated due to cultural differences.

The three terms are used interchangeably, although they represent different ways of contributing to a group. Cooperation can be achieved if all participants do their assigned parts separately and bring their results to the table, while the collaboration implies direct interaction among the partners to reach the desired result. This interaction often involves negotiations, discussions, and consideration of different perspectives. In other words, cooperation focuses on working together to create an end product, while participants in collaboration share in the process of knowledge creation [5]. Therefore, the collaboration is appropriate for complex projects involving multiple teams or agencies, while the cooperation is suitable for projects in which each participant is responsible for performing a certain segment of the complete task. In both cases, partnership also frequently occurs.

It is to be mentioned here that the opposite of cooperation or collaboration is "competition." A small amount of competition is effective in encouraging different organizations to seek a better position, but excessive levels of competition have negative consequences. Many institutions cooperate in research and collaborate in the research and joint degrees, but still see each other as "competitors" as they try to attract the best students and staff and to get higher rankings.

\subsection{King Abdulaziz University's Choice to Pursue Collaboration}

King Abdulaziz University (KAU) realized early on the importance of international university cooperation and collaboration to expedite its way toward becoming a world-class university. As a result, it has established joint 
international cooperation agreements and service contracts with many of the world's distinguished universities and educational institutions. It has also established the Distinctive Scientists Program to create collaboration programs between KAU researchers and well-known researchers from all over the globe. These steps, along with other accomplishments, have accelerated the achievement of KAU's objective to increase its ranking and become a world-class university.

\section{International Collaboration}

International cooperation and collaboration are modes of working together to attain the best results in the development of solutions to international problems. Modern life has brought luxury to human beings, but at the same time, it has created many massive problems such as global warming, an extreme need for energy, excessive demand for water, crowded cities, the rapid aging of people, and a high occurrence of natural disasters. These huge problems necessitate collaboration between universities and industry worldwide to bridge the gap between knowledge and innovation.

A comprehensive paper by Ankrah and Al-Tabbaa [6] on universities-industry collaboration (UIC) for the period from 1990-2014 studied the different organizational forms of UIC, motivations at universities and in industry for UIC, the process of forming UICs, activities undertaken in UICs, the factors facilitating or impeding UICs, and the benefits from UICs for both the universities and the industry. The paper explains that collaboration between universities and industry is increasingly perceived as a vehicle to enhancing innovation through knowledge exchange. This is evident from the significant increase in studies that investigate the topic from different perspectives.

The academia-industry collaboration in science and technology-based innovation has resulted in role sharing between universities and companies resulting in global problem solving with an emphasis on human resources development.

International cooperation and collaboration are carried out between partners working traditionally together in the same field or collaboratively in various fields in order to find an optimized solution or to introduce a non-traditional or creative solution for an international problem. The climate problem, growing energy consumption, high rates of fatal car accidents, global peace, and fighting terrorism and crime are the most famous examples of widespread global problems. To find the best scientific and applicable solutions to such problems requires the strengthening of cooperation/ collaboration between universities, research institutions, civil societies, and industrial sectors. At times, international policies have a key role to play in developing appropriate solutions and preparing them for implementation.

The following section, Sect. 3, deals with how international collaboration is implemented by higher education institutions, while Sect. 4 explains the importance of international collaboration for universities.

\section{International Collaboration and Cooperation Among Universities}

International university collaboration is a part of the much wider arena of international collaboration. The topic of international university collaboration has been prominent in recent times and has become a significant and important university activity [7]. In recent years, universities have managed to include international cooperation and collaboration as integral elements of their missions and functions although it is a laborious process. This cooperation and collaboration are forms of working together to attain the best results in learning, training, and research.

University cooperation has recently been successfully incorporated into the institutional structure of an increasing number of universities. Most universities currently have an office or administration in charge of international university cooperation, with a definite strategy and an action plan to carry out a series of international activities. In recent years, rising expectations have been generated with regard to the need to adopt new perspectives in international university cooperation. University authorities have to overcome budgetary constraints and other impediments in order to pursue the necessary efforts to enhance the incorporation of international cooperation in their institutions.

For a long time, education and scientific research have been focused on a lot in international cooperation/ collaboration. Therefore, universities and research institutions are called upon to promote cooperation in order to develop knowledge, which will benefit all humankind [7]. Recently, introducing international collaboration as one of the university strategic objectives has opened new paths for the exchange of academic expertise, saving effort and money and achieving qualitative leaps in strengthening systems management and development.

Technical international cooperation is another form of international university cooperation. It includes activities whose primary aim is to increase the level of knowledge, technology, practical know-how or productive attitudes of the population, that is to say, to increase their reserve of human intellectual capital or their ability to use their current resources with greater efficiency [8]. The basic aim of technical cooperation is to support the ability of people and organizations in creating, adapting, strengthening, and sustaining their capacity to set their own objectives. Its aims are 
that institutions with a more advanced level of development in certain areas would contribute to the solution of specific problems of less developed institutions through the transference and interchange of scientific and technological capacity and human and material resources.

Technical cooperation is often associated with actions intended to strengthen individual and organizational capacity by offering a wide range of technical opportunities to its beneficiaries. Technical cooperation can be strengthened via improving the following cooperative channels:

- Educational cooperation: student exchange, teacher exchange, language learning, joint degrees, and curricula developments

- Research cooperation: joint research activities

- Training cooperation: training programs and supplying training equipment and materials

- Cultural cooperation: social and cultural programs

- Scholarships

- Strategic partnerships.

\section{The Importance of International Collaboration for Universities}

International partnerships between universities are beneficial to all, including staff and students. Forming links with other universities has become highly necessary and is easily managed. Universities across the world are seeking to form global partnerships and foster relationships with other institutions. This helps student recruitment in two main ways: For domestic students, it offers the opportunity to travel internationally via student exchange programs, and vice versa for students at partnered universities. It also enables universities to better understand the culture of other nations [9]. Additionally, international collaboration programs help by providing students with the ability to study, work, and travel worldwide.

Partnerships with highly ranked international universities provide greater opportunities for cultural exchange and the development of academic systems, which in turn will positively reflect on the development of various academic and research university sectors. Developing the abilities and skills of human resources from student to professor is the most significant factor in the strategic development process. For these benefits, universities all over the world seek to create international partnerships with similar universities and academic institutions. Academic exchange programs, including international visits, enable students and staff members on both sides to learn about each other's culture. Such programs also promote intercultural skills in a globalized world, help people to work effectively in a new environment, open new channels for academic cooperation, and help people to make new friendships. This has a direct effect on university development processes and the quality of academic and research programs.

Significantly, it is known that one in five of the world's scientific papers is co-authored internationally. As a result of the expansion of communication methods, academics and researchers are finding it easier to collaborate with their foreign counterparts, and the exchange of academic ideas has become much simpler to organize.

The ability to scrutinize, debate, and share experience is essential for academic and scientific accomplishment. International collaborations help to facilitate this. In terms of teaching, benefits include curriculum development and degrees formed in collaboration with partner institutions. However, developing successful relationships takes a long time and requires understanding the culture and goals of each other's institutions in order to ensure compatibility in terms of ethics and standards. Therefore, the most important aspect of a partnership's endurance is an alliance of ideas and goals. This means selecting carefully institutions to partner with and confirming at every stage that all members of the partnership are on the same page [9].

\section{International Collaboration in Higher Education in Saudi Arabia}

International cooperation in higher education in Saudi Arabia is a part of the strategic goal of the Ministry of Education (MOE). It aims to develop, improve, enhance, and raise the level of higher education in the country through cooperation with distinguished international higher education and research institutions. This is achieved via signing agreements and alliances and by building international partnerships in academic and research areas [10]. The MOE has established the "General Administration for International Cooperation" within its administrative structure. The unit was established because of the Ministry's belief in the importance of international cooperation mechanisms in education and their strong effects on fostering globalization, massification, and marketization of higher education.

The objective of the General Administration of International Cooperation is to ensure effective mutually beneficial coordination with universities and academic research agencies outside the kingdom. It has an important role in building bridges of knowledge between Saudi universities and 
Fig. 1 Administration of international agreements at KAU

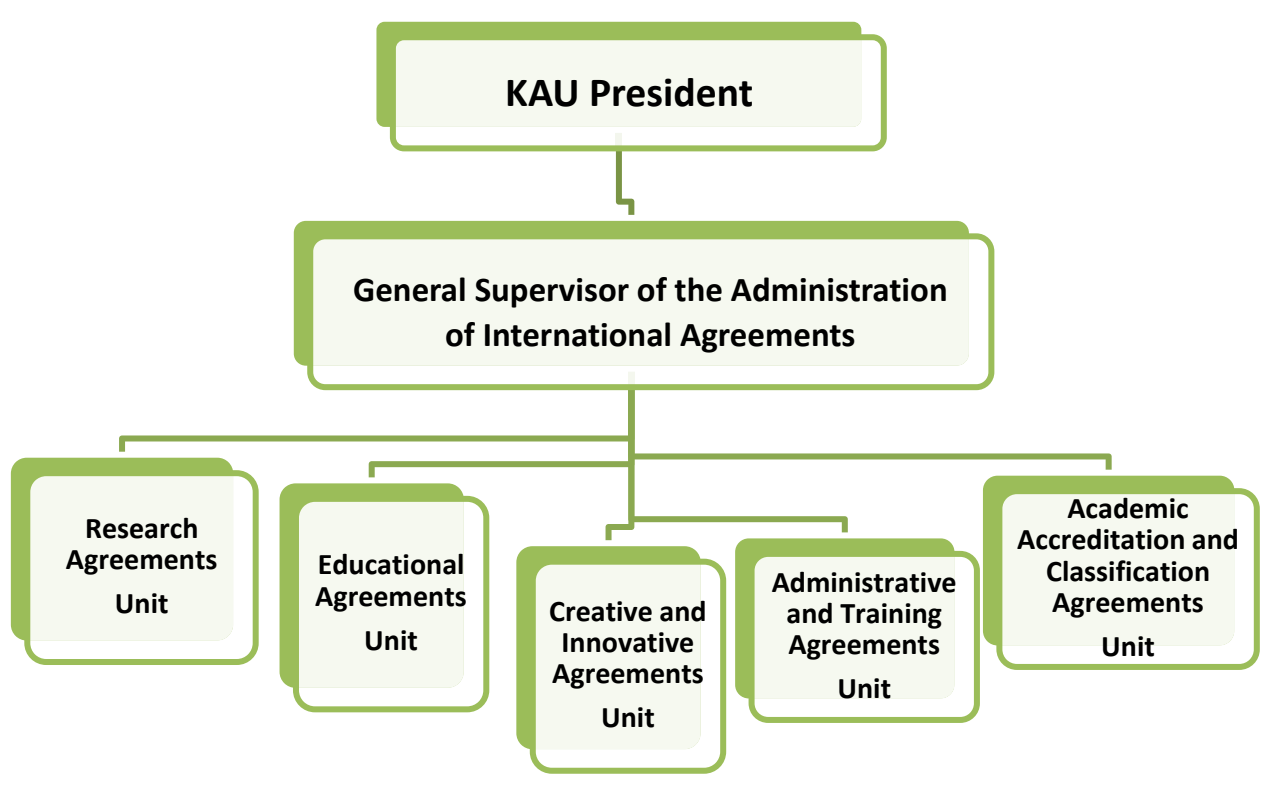

internationally prestigious and distinguished higher educational institutions. It seeks to promote knowledge and cultural exchange through the expansion of scholarships. It coordinates training programs, seminars, conferences, and international exhibitions, and it raises the level of performance and development of international cooperation in various fields of knowledge. The administration is eager to contribute to, highlight and reinforce Saudi Arabia's general development in the field of higher education. The MOE and the Saudi universities have signed a number of memorandums of cooperation and service contracts with ministries and prestigious universities around the globe.

\section{International Collaboration at King Abdulaziz University}

This section discusses the international collaborations at King Abdulaziz University (KAU).

\subsection{KAU Administration of International Agreements}

At $\mathrm{KAU}$, there is an "Administration of International Agreements" that organizes, follows up, and develops international agreements between KAU and international universities and research centers. The aim is to accelerate scientific progress and expedite technology transfer from the world's most prestigious universities and scientific institutes to KAU. The administration prepares a fully automated management system of international agreements and service contracts and ensures that adequate budgetary provisions are in place for effective task design and implementation. It also edits a final statistical analysis report detailing the achievements of the various agreements.

The structure of the administration is illustrated in Fig. 1. It consists of five units under the management of a general supervisor who reports directly to the KAU President. However, to ensure administrative effectiveness, the University Vice Presidents monitor and supervise the five units according to their fields of responsibility. The Research Agreements Unit is under the supervision of the Vice President for Graduate Studies and Scientific Research, while the Educational Agreements Unit is under the supervision of the Vice President for Academic Affairs. The Creative and Innovative Agreements Unit is under the supervision of the Vice President for Business and Knowledge Creativity, while the Administrative and Training Agreements Unit is under the supervision of both the Vice President and the Vice President for Development. And finally, the Academic Accreditation and Classification Agreements Unit is under the supervision of the Vice President for Development.

\subsection{Agreements with Leading Universities}

King Abdulaziz University has made joint international cooperation agreements and service contracts with many of the world's top universities and educational institutions. There are currently more than 77 operational service contracts and several other agreements and memorandums of understanding between KAU and universities, scientific institutions, and specialized companies in many countries such as the USA, Canada, and Argentina in the Americas; the UK, France, Spain, Germany, Finland, Switzerland, 
Austria, the Netherlands, Belgium and Turkey in Europe; China, South Korea, Japan, Singapore and Malaysia in Asia; and Australia and New Zealand in the South Pacific. These agreements and service contracts specialize in the implementation of joint research projects and patents; the exchange of students, staff, faculty members, and scientific expertise; the establishment of joint graduate programs; curriculum development; the development of distance education; training programs for medical, engineering, and maritime studies graduate students; and training for faculty members.

\subsection{International Students Program}

The international graduate students program started some years ago and is successfully attracting students from different countries. KAU grants scholarships to talented international students to pursue their studies in its various university graduate programs. KAU admits top international students in its graduate programs. Currently, KAU has 193 graduate programs in all of its specializations, divided into Ph.D. (43), Master's degree (143), and Higher Diploma (7). Recently, the number of new entrants has increased significantly, and this growth has necessitated strengthening and invigorating all aspects of higher educational academic research at KAU. This has helped to ensure that when KAU graduates enter the employment market, their competencies and qualifications are sought after and welcomed by international employers. KAU has become a recognized venue for "elite higher education." It has a reputation for academic excellence and is considered to represent quality higher education. These factors enable KAU to have the privilege of receiving high levels of funding and to recruit the most academically talented international students.

\subsection{Distinguished Scientist Program}

The 9th Development Plan of the Kingdom of Saudi Arabia states that it will concentrate on scientific research and attract scientists of high caliber to work in universities and research centers. The 2005-2030 Plan of Higher Education in Saudi Arabia (AAFAQ Plan) states that universities should attract the best scientists, while the KAU Strategic Plan states that it will be transformed into a Research University. The International Advisory Board (IAB) of KAU suggested in its second meeting (July 2011) that KAU should attract internationally distinguished scientists to enhance its research quality. Accordingly, in June 2011, KAU started an ambitious program to employ distinguished scientists. Colleges, Research Groups, and Centers search for distinguished scientists whose specialization fits the research areas and send their selection to a KAU committee which starts writing to the selected distinguished scientists inviting them to visit KAU and meet with the local scientists to discuss possible types of collaboration. At the end of the visit, a decision is taken as to whether to go ahead with the collaboration or not. Many distinguished scientists have preferred to work part-time, while a few have moved to KAU.

The duties of the distinguished scientists can be summarized as follows: to write research proposals with KAU researchers to the KAU Deanship of Scientific Research and to the King Abdulaziz City of Science and Technology (KACST), especially for the National Strategic Research Program; to collaborate with and guide the local academic staff to conduct the research; to co-supervise graduate students; to examine graduate students theses; to give seminars, lectures, and short courses; to co-author books; to participate in establishing business incubators; to participate in the councils of the centers of research excellence; to help KAU graduates to get admission in graduate programs at universities abroad; and to help KAU academic staff get acceptance for Sabbatical years in their home universities.

The outcome of the program may be summarized in the following points: Numerous research proposals have been submitted to the KAU Deanship of Scientific Research by distinguished scientists in collaboration with more than 150 KAU academic staff; numerous research proposals have been submitted to King Abdulaziz City for Science and Technology (KACST); various scientific books have been published; four international scientific journals have been launched: Bulletin of Mathematical Sciences (published by Springer), The Journal of Microscopy and Ultrastructure (published by Elsevier), Genomic Medicine (published by Nature Partner Journals, NPJ), and Climate and Atmospheric Science (published by Nature Partner Journals, NPJ).

\subsection{International Advisory Board (IAB)}

King Abdulaziz University (KAU) has undertaken genuine transformational steps to establish partnerships and cooperative programs with international educational and industrial institutions in order to enhance and improve its academic and educational profile and status. To achieve a substantive leap forward in quality in levels of performance in educational, academic research, and community services, in 2010, KAU established an International Advisory Board (IAB). It is benefiting from the experience of international pioneers in the industry and higher education who have made significant contributions to the development of higher education worldwide. The aim of the IAB has been to provide KAU with diverse input and guidance from the international community in order to support its quest for academic and educational excellence and ultimately, its international 
recognition. To ensure that KAU receives a diversity of ideas and views, the IAB represents a variety of disciplines and an extensive range of backgrounds.

The main objectives of the IAB are: to participate in re-formulating KAU's strategic plans; to achieve its goals in the educational process, scientific research, and community service; to enable the university to surpass and accomplish distinction in knowledge accumulation, science, and technology; to enhance the university's status and international profile, especially in the fields of research and innovation; to contribute to the formation of strategic alliances between KAU and different sectors in the Saudi community, as well as international institutions; to establish and activate partnerships with international universities and research centers; and to provide consultancy to KAU as well as to other Saudi institutions wishing to take advantage of the expertise, experience, and qualifications of IAB members [11].

\subsection{Research Groups}

KAU initiated the idea of forming research groups to enhance cooperation between researchers from different specializations. Each group consists of up to 15 researchers and academics (of all ranks including fresh academics and graduate students) under the leadership of one prominent scientist. The group must include one collaborating scientist from an international university. Each research group has a main broad specialization that is different from the specializations of other groups. The research proposals submitted by research groups are prioritized in terms of funding over proposals submitted by individuals. To date, twenty-five research groups have been formed covering a wide spectrum of specializations. These are the: Saudi Diabetes Research Group; Oral and Dental Diseases Research Group; Renewable Energy Group; Software Engineering and Distributed Systems Group; Economic and Market Research Group; Nonlinear Analysis and Applied Mathematics Group; Biotechnology Group; Engineering Management and Quality Improvement Group; Information Security Research Group; Advances in Composites, Synthesis and Applications Group; Clinical Nutrition Group; Communication Systems and Networks Group; Plant Biology Group; Laser Applications Group; Diagnostic and Therapeutic Engineering Group; Modeling and Simulation of Complex Systems Group; Bioactive Natural Products Group; Medicinal Plants Group; Lithography in Device Fabrication and Development Group; Metal Oxides Research Group; Carbon Nanostructures Group; Vitamin D Pharmacogenomics Group; Virtual Reality Research Group; Sustainable Green Chemistry Group; and Sleep Disorder Research Group.

In addition to publishing papers in ISI ranked journals, the research groups are committed to working on projects that benefit the local community as well as the national Saudi community.

\subsection{KAU-Industry Collaboration}

Collaboration between KAU and industry is managed by the Research and Consulting Institute (RACI). RACI is a consultation center which provides its services in research and development on a contractual basis with the utmost flexibility and professionalism to suit both the public as well as the private sectors. RACI is one of the most important investment arms of KAU. It offers a number of services including: contractual research, consultancy, project management, educational services, and training. In addition, RACI manages KAU's scientific chairs and central laboratories.

The objectives of RACI are to have a strong partnership with the society based on KAU's responsibility toward the country and its citizens; to have a modern methodology for providing consultation experiences that meet international standards; and to market KAU human and technical abilities via professional and competitive ways.

The capabilities of RACI include: a strong relationship with effective players in the consulting service industry; access to more than 5000 researchers from various specialties at KAU to perform services offered by RACI such as contractual research, consultations, training, and educational services; more than 50 central laboratories at medicine, engineering, computing, science, and business schools, which can provide different services to both the public and the private sectors; and more than 200 active expert houses that offer consulting services to various sectors in the kingdom. These expert houses cover most of the fields including medicine, engineering, computing, science, economics, and business.

\subsection{Knowledge and Business Alliance}

In addition to the Research and Consulting Institute, KAU and the public and private sectors also collaborate through the Knowledge and Business Alliance $(\mathrm{K} \& \mathrm{~B})$. As the largest and one of the most prominent universities in Saudi Arabia, KAU has a proven record in providing research solutions. KAU has at its disposal about 50 years' worth of "know-how" and organizational knowledge competence, in addition to a magnitude of other resources and assets including: rich expertise and established industry leadership; state-of-the-art research infrastructures; and a stimulating working environment. KAU clients and partners are diverse, ranging from entrepreneurs to developers, from locals to internationals, and from visitors to tenants. However, they 
have one aspect in common: They are empowered through the synergy of KAU knowledge partners. K\&B facilitates the creation of these knowledge networks through its four main divisions:

(1) Expert Houses Sector: Drawing on KAU's powerful knowledge base of varied specializations and highly qualified academic personnel, these are universitysupervised, faculty-operated establishments that offer specialized consulting services to both private and public sectors.

(2) Central Laboratories Sector: These laboratories provide a powerful combination of expertise, competent staff, and state-of-the-art equipment dedicated to providing specialized and advanced laboratory consultations and workshop services, including standardized procedures, certified tests, and analytical studies.

(3) Business Incubators Sector: This sector offers valuable support services and resources to KAU students and graduates with promising and innovative business ideas and projects. Moreover, it helps entrepreneurial firms survive and grow during vulnerable start-up phases.

(4) Knowledge Parks Sector: These parks provide a smart and stimulating working environment which enables tenants to reduce their cost of operation and to enhance their competitiveness through privileged access to KAU's professors, students, labs, cutting-edge technological infrastructure, and a wealth of other supporting services.

\subsection{Wadi Jeddah (Jeddah Valley) Company}

Another channel for collaboration with industry is the Wadi Jeddah Company. It is wholly owned by KAU and represents KAU's investment arm. It operates on a commercial basis in the process of investment and profitability and contributes to the development of the knowledge economy. To achieve its goals, Wadi Jeddah has established five companies so far. These are:

(1) Molecular Imaging Center: This was established due to the increasing need for a specialized center in cancer diagnosis as well as in the production of the radioactive materials needed in the diagnosis. The company has partnered with the General Electric Company to operate the project.

(2) Manarat Al-Ma'arefa (Knowledge Minarets): This was established for knowledge transfer and R\&D. It works on creating a suitable environment to attract scholars and businesspeople.
(3) Saudi Alliance for Development of Education and Training (SAFEA): This project is implemented through a partnership contract with the Finnish company, EduCluster, which comes under the University of Jyväskylä, one of the largest universities in Finland known for its multidisciplinary activities in creativity and innovation in the field of education and research.

(4) Medical Knowledge Village: This company plans to build a hospital and a hotel of international standard on the Obhur Campus (North Jeddah) of KAU.

(5) Clinical Research Organization: This medical research company is to be a model center for conducting clinical research on drugs. It plans to establish partnerships with international pharmaceutical companies.

\section{Outcomes of Collaboration at King Abdulaziz University}

King Abdulaziz University constitutes a rich source of graduates and skilled cadres which can help address the needs of the country and contribute to its development. To achieve its objectives and become one of the top universities in the world, KAU adopts a clear vision, responds accordingly to changing community needs and circumstances, provides a congenial academic environment, and establishes cultural cooperation with international universities. This results in the university having outstanding educational programs, skilled graduates, rich scientific research, and the ability to make effective contributions to society. The need for excellence in international relations is triggered by the diversity of the university's departments and the importance of coordinating collaboration and cooperation with other universities.

The KAU Vision regarding international cooperation is to establish internationally effective partnerships to support the university's vision, while its message is to participate in the development of the university into a leading international, cultural, scientific, and research collaboration.

The achievements of the international agreements held between King Abdulaziz University and world-class universities have resulted in eighty-one agreements in various fields. The total budget of these agreements has amounted to more than US $\$ 120$ million. The achievements include: publishing numerous scientific papers in ISI journals and specialized international conferences; registering numerous patents at international organizations; implementing 1400 training, development or technology transfer programs; developing graduate programs; and developing student and professor exchange programs. 


\section{Conclusion}

International university cooperation is a must, especially for university students and professors in the early stages of their careers. International cooperation and collaboration should be an integral element of the university mission and functions. This is achieved by universities when they assume responsibility for cooperating with other world-class institutions. International university collaboration and cooperation can take place in many avenues of university work: education, research, training, culture cooperation, and scholarships.

Research cooperation among individuals is no longer complicated, even though these researchers work at institutions in different countries and have cultural differences. Modern communication methods have facilitated the research projects they conduct. Globally, student exchange is increasing, and the total number of Saudi students studying abroad has also grown rapidly in recent years, largely funded by the Saudi government scholarship programs. International student and staff exchange increases the concerned individuals' capacity for self-reflection, self-reliance, and self-confidence. Such exchanges also help individuals develop more mature and objective perceptions concerning their home and foreign countries, thereby contributing to international tranquility by enhancing multicultural understanding. Such an exchange also crucially promotes creative thinking.

International collaboration and cooperation in higher education is a strategic goal of the Saudi Ministry of Education. In line with this goal, the MOE is actively involved in building bridges of knowledge between Saudi universities and world distinguished educational institutions to promote knowledge and cultural exchange. Each Saudi university, including King Abdulaziz University, has established joint international cooperation agreements and service contracts with many of the world's top-ranking distinguished universities and educational institutions. The international strategic policy of world-class universities is intended to improve education, strengthen both external and internal collaboration, build research partnerships with other world-class universities, and attract highly talented students and professors from around the world. Success in so doing provides a diversity of academic environments and scientific approaches and is a mark of distinction and strength.

Any world-class university endeavors to develop its leading position by providing researchers and students with excellent opportunities for cooperation, collaboration, and exchange with other national and international universities. Successful implementation of this strategy enables the university's researchers and students to participate in international research and research-based teaching to acquire a truly global outlook. Such a strategy can be implemented by means of research projects, student symposia, summer programs, workshops, conferences, and congresses. Scholarship grants and programs, such as the "International Students Program" of KAU promote mutual understanding between individuals and institutions in the global arena. Such mutual and mutually beneficial understanding can be accomplished through the educational and cultural exchange of students, knowledge, and skills and is of crucial significance to mankind's aspirations to live in harmony and peace.

Other cooperative programs provide opportunities for study, lecturing, curricular development, postdoctoral research, advanced joint research grants, visits, and aid in promoting mutual cultural understanding. Such programs also assist in the internationalization of campuses, curricula, and communities. Grant programs facilitate an international educational and cultural exchange for students, teachers, professionals, and scientists. This exchange is accomplished through direct interactions of individuals who are able to live and work together in order to learn from host country inhabitants in a daily sharing of mutually enriching cultural experiences.

King Abdulaziz University realized early on the importance of international university cooperation and collaboration to expedite its way toward becoming a world-class university. The impact of this on KAU has strengthened its scientific research and higher education sector (international students), improved the quality of its academic programs, and facilitated the administrative development and restructuring of KAU through its successive strategic plans. International collaboration has achieved alignment between KAU's vision and objectives and the programs of the Kingdom of Saudi Arabia Vision 2030. Enhancing the ranking of KAU is an outcome of the development plans and activities based on international collaboration.

And finally, it is worth mentioning that although some other Saudi universities have similar programs of collaboration, none of them have all the programs of KAU. It is no wonder that KAU is ranked as the top Saudi university in the list of world university rankings (Shanghai, Times, and QS). KAU was declared by the Times Higher Education ranking to be the top university in the MENA region for two successive years (2017 and 2018).

Acknowledgements The authors of this chapter would like to thank Prof. Mahmoud Nadim Nahas and Prof. Ahmad Hegazy for collecting the data needed for the manuscript. 


\section{References}

1. Roschelle, J., \& Teasley, S. (1995). The construction of shared knowledge in collaborative problem solving. In C. E. O'Malley (Ed.), Computer supported collaborative learning (pp. 69-97). Heidelberg: Springer.

2. Keohane, R. (1984). After hegemony: Cooperation and discord in the world political economy. Princeton: Princeton University Press.

3. Gonzales-Tablas, M. A. (1995). Visión Global de la Cooperación para el Desarrollo. Barcelona: Icaria Editorial.

4. Dillenbourg, P., Baker, M., Blaye, A., \& O’Malley, C. (1996). The evolution of research on collaborative learning. In E. Spada \& P. Reiman (Eds.), Humans and machine: Towards an interdisciplinary learning science (pp. 189-211). Oxford: Elsevier.

5. Kozar, O. (2010). Towards better group work: Seeing the difference between cooperation and collaboration. English Teaching Forum, 48(2), 16-23.

6. Ankra, S., \& Al-Tabbaa, O. (2015). Universities-industry collaboration: A systematic review. Scandinavian Journal of Manag- ement, 31(3), 387-408. https://doi.org/10.1016/j.scaman.2015.02. 003.

7. Development Cooperation Directorate. Website, Organization for Economic Cooperation and Development (OECD). http://www. oecd.org/dac. Accessed March 30, 2019.

8. Technical cooperation for capacity development. Perspectives note, OECD/DAC Report, 2011. http://www.oecd.org/dac/ governance-development/48260262.pdf. Accessed March 30, 2019.

9. QS Digital Marketing. Why are international collaborations so important for universities? http://www.qs.com/why-are-interna tional-collaborations-so-important-for-universities/. Accessed Ma rch 30, 2019.

10. Saudi Ministry of Education. https://departments.moe.gov.sa/ InternationalCooperation/Pages/default.aspx. Accessed March 30, 2019.

11. Tayeb, O., Zahed, A., \& Ritzen, J. (Eds.). (2016). Becoming a world-class university: The case of King Abdulaziz University. Cham, Switzerland: Springer.
Open Access This chapter is licensed under the terms of the Creative Commons Attribution 4.0 International License (http:// creativecommons.org/licenses/by/4.0/), which permits use, sharing, adaptation, distribution and reproduction in any medium or format, as long as you give appropriate credit to the original author(s) and the source, provide a link to the Creative Commons license and indicate if changes were made.
The images or other third party material in this chapter are included in the chapter's Creative Commons license, unless indicated otherwise in a credit line to the material. If material is not included in the chapter's Creative Commons license and your intended use is not permitted by statutory regulation or exceeds the permitted use, you will need to obtain permission directly from the copyright holder. 